\title{
Chronic Corneal Epithelium Abrasion with Pellet Stove Heating
}

\author{
Marco Zeppieri * \\ Department of Ophthalmology, University Hospital Santa Maria della Misericordia, Italy \\ *Corresponding author: Marco Zeppieri, Department of Ophthalmology, University Hospital Santa Maria della \\ Misericordia, Italy
}

\begin{tabular}{|c|c|}
\hline ARTICLE INFO & ABSTRACT \\
\hline Received: 幽 February 27, 2020 & Citation: Marco Zeppieri. Chronic Corneal Epithelium Abrasion with Pellet Stove Heating. \\
\hline Published: 蔧 March 06, 2020 & Biomed J Sci \& Tech Res 26(3)-2020. BJSTR. MS.ID.004345. \\
\hline
\end{tabular}

\section{Editorial}

I would like to share an interesting case report in which the doctor becomes a patient. As an ophthalmologist working in a main public hospital, I see numerous cases of epithelium corneal abrasions due to several factors, which include trauma, dry eye syndrome, infection, contact lens users, autoimmune systemic diseases, etc. [1-3] In the winter of 2014, I began to suffer from chronic eye irritation and sensation of foreign body in both eyes. My Chief and other colleagues confirmed after numerous slit-lamp examinations that there were no signs of infection or observable foreign bodies under the lids or in the conjunctiva; however, there were signs of moderate inflammation and superficial corneal abrasion. After months of therapy $[4,5]$ with artificial tears, anti-inflammatory drops, and cortisone, the symptoms did not improve. We tried to search for the causes of this onset of ocular signs and symptoms, but nothing seemed to explain my problems. I suffer from allergies due to pollen, but I never experienced allergic conjunctivitis. There were no carpets, pets or other sources of potential allergens in the home or in the clinic. The only change in the house was the heating with the new pellet stove. This type of heating offers numerous advantages [6,7]. I tried to place humidifiers in each room for fear that the eye irritation was due to the dry environment with the new source of heating. Over three months I tried about a dozen different types of wood pellets for fear that I was allergic to the components, but this did not seem to solve the problem. The sensation of sand with burning were the main symptoms without itching, thus the cause was probably not due to an allergic component.

Upon speaking to a friend of mine that is a carpenter, he suggested that the problem could be explained by the fine dust emitted by the pellet and ashes when loading or cleaning the stove. At first I thought this could not be the explanation considering there appeared to be less dust in the house with the new heating system [6] He suggested using swimming goggles that completely sealed the eyes to avoid any particles entering the eye when cleaning and loading the stove. I normally wear glasses for myopia, so I assumed that this could not be the cause because my normal glasses protected my eyes from large foreign bodies. To my great surprise, this technique solved the mysterious problem that I had been suffering for months. Apparently the fine particles of dust and ashes emitted when filling and cleaning the stove were acting like sand paper and creating this chronic abrasion, without showing signs of foreign bodies in the eye due to the tiny size of the particles not easily visible with the human eye and during slit-lamp examination. Having undergone this period of corneal epithelium abrasion, I realized that pain and dryness sometimes occurred even after years. This was clearly more prominent during very hot, cold or windy seasons due to the environment conditions that promote dry eye [8] What I couldn't understand was that the symptoms tended to occur more frequently during sleep, especially after drinking alcohol. It occurred to me that the striking pain could be due to the rapid eye movement during the REM phase of sleep that acted on rubbing the epithelium across the inner lid conjunctiva, which at times cause abrasion in my already sensitive corneas. Moreover, this became more frequent after drinking, which could 
be explained by the dehydration to the entire body, including the eye (with induced tear hyperosmolarity and shortened break up time), $[8,9]$ which is also the cause for the nasty hangover the day after. Pellet stove users are warned on how to properly use the stove pellet and how to avoid potential dangers. I think it is important to advise those who choose this form of heating that corneal abrasions can arise due to the pellets and ashes. It is thus best to always use glasses that completely seal the eyes from the external environment whenever in close proximity to the pellet stove, especially when loading and cleaning it. And remember to hydrate your eyes and body before going to bed if you have sensitive eyes, especially after a night on the town: doctor's orders!

\section{References}

1. Ahmed F, House RJ, Feldman BH (2015) Corneal Abrasions and Corneal Foreign Bodies. Prim Care 42(3): 363-375.

2. Barrientez B, Nicholas SE, Whelchel A, Sharif R, Hjortdal J, et al. (2019) Corneal Injury: Clinical and Molecular Aspects. Exp Eye Res 186: 107709.

3. Lim CH L, Stapleton F, Mehta JS (2018) Review of Contact Lens-Related Complications. Eye Contact Lens 44(Suppl 2): S1-S10.

\section{ISSN: 2574-1241}

DOI: $10.26717 /$ BJSTR.2020.26.004345

Marco Zeppieri. Biomed J Sci \& Tech Res

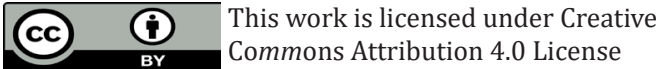

Submission Link: https://biomedres.us/submit-manuscript.php
4. Waldman N, Winrow B, Densie I, Gray A, McMaster S, et al. (2018) An Observational Study to Determine Whether Routinely Sending Patients Home With a 24-Hour Supply of Topical Tetracaine From the Emergency Department for Simple Corneal Abrasion Pain Is Potentially Safe. Ann Emerg Med 71(6): 767-778.

5. West JR (2019) Are Topical Nonsteroidal Anti-Inflammatory Drugs Useful for Analgesia in Patients With Traumatic Corneal Abrasions? Ann Emerg Med 73(2): 157-159.

6. Champion WM, Grieshop AP (2019) Pellet-Fed Gasifier Stoves Approach Gas-Stove Like Performance During in-Home Use in Rwanda. Environ Sci Technol 53(11): 6570-6579.

7. Tanaka M, Yamada H, Nakamura T, Watanabe Y (2012) Effects of Pellet Stove on Recovery From Mental Fatigue. Med Sci Monit 18(3): CR148CR153.

8. Asiedu K, Kyei S, Boampong F, Ocansey S (2017) Symptomatic Dry Eye and Its Associated Factors: A Study of University Undergraduate Students in Ghana. Eye Contact Lens 43(4): 262-266.

9. Kim JH, Kim JH, Nam WH, Yi K, Choi DG (2012) Oral Alcohol Administration Disturbs Tear Film and Ocular Surface. Ophthalmology 119(5): 965-971.

$\begin{array}{ll}\text { BIOMEDICAL } & \text { Assets of Publishing with us } \\ \text { RESEARCHES } & \text { - Global archiving of articles } \\ & \text { - Immediate, unrestricted online access } \\ & \text { - Rigorous Peer Review Process } \\ & \text { - Authors Retain Copyrights } \\ \end{array}$

